University of Nebraska - Lincoln

DigitalCommons@University of Nebraska - Lincoln

U.S. Department of Veterans Affairs Staff

Publications

U.S. Department of Veterans Affairs

2010

\title{
Malondialdehyde-acetaldehyde adduct is the dominant epitope after MDA modification of proteins in atherosclerosis
}

\author{
Michael J. Duryee \\ University of Nebraska Medical Center, mduryee@unmc.edu \\ Lynell W. Klassen \\ University of Nebraska Medical Center, Iklassen@unmc.edu \\ Courtney S. Schaffert \\ University of Nebraska Medical Center, cschaffert@unmc.edu \\ Dean J. Tuma \\ University of Nebraska Medical Center, dean@tuma.net \\ Carlos Hunter \\ University of Nebraska Medical Center, chunter@unmc.edu \\ See next page for additional authors
}

Follow this and additional works at: https://digitalcommons.unl.edu/veterans

Duryee, Michael J.; Klassen, Lynell W.; Schaffert, Courtney S.; Tuma, Dean J.; Hunter, Carlos; Garvin, Robert P.; Anderson, Daniel R.; and Thiele, Geoffrey M., "Malondialdehyde-acetaldehyde adduct is the dominant epitope after MDA modification of proteins in atherosclerosis" (2010). U.S. Department of Veterans Affairs Staff Publications. 36.

https://digitalcommons.unl.edu/veterans/36

This Article is brought to you for free and open access by the U.S. Department of Veterans Affairs at DigitalCommons@University of Nebraska - Lincoln. It has been accepted for inclusion in U.S. Department of Veterans Affairs Staff Publications by an authorized administrator of DigitalCommons@University of Nebraska - Lincoln. 


\section{Authors}

Michael J. Duryee, Lynell W. Klassen, Courtney S. Schaffert, Dean J. Tuma, Carlos Hunter, Robert P. Garvin, Daniel R. Anderson, and Geoffrey M. Thiele 


\title{
Malondialdehyde-acetaldehyde adduct is the dominant epitope after MDA modification of proteins in atherosclerosis
}

\author{
Michael J. Duryee a,b,*, Lynell W. Klassen ${ }^{\mathrm{a}, \mathrm{b}}$, Courtney S. Schaffert ${ }^{\mathrm{a}, \mathrm{b}}$, Dean J. Tuma ${ }^{\mathrm{a}, \mathrm{b}}$, Carlos D. Hunter ${ }^{\mathrm{a}, \mathrm{b}}$, \\ Robert P. Garvin c , Daniel R. Anderson c, Geoffrey M. Thiele ${ }^{\mathrm{a}, \mathrm{b}, \mathrm{d}}$
}

a Experimental Immunology Laboratory, Section of Rheumatology, Department of Internal Medicine, University of Nebraska Medical Center, Omaha, NE 68198, USA

b Experimental Immunology Laboratory, Omaha Veterans Administration Medical Center, Omaha, NE 68105, USA

c Experimental Immunology, Research in Cardiovascular Disease Laboratory, Section of Cardiology, Department of Internal Medicine, University of Nebraska Medical Center,

Omaha, NE 68198, USA

d Department of Pathology and Microbiology, University of Nebraska Medical Center, Omaha, NE 68198, USA

\section{A R T I C L E I N F O}

\section{Article history:}

Received 8 June 2010

Revised 14 July 2010

Accepted 2 August 2010

Available online 6 August 2010

Keywords:

Atherosclerosis

Modified proteins

Acetaldehyde

Malondialdehyde

Autoantibodies

Lipid peroxidation

JCR rats

\begin{abstract}
A B S T R A C T
Antibodies to malondialdehyde (MDA)-modified macromolecules (adducts) have been detected in the serum of patients with atherosclerosis and correlate with the progression of this disease. However, the epitope and its formation have not been characterized. Studies have shown that excess MDA can be degraded to acetaldehyde, which combines with proteins to from a stable dihydropyridine adduct. To investigate, mice were immunized with MDA adducts in the absence of adjuvant and showed an increase in antibodies to MDA adducts and the carrier protein as the concentration of MDA was increased. In fact, a number of the commercially available antibodies to MDA-modified proteins were able to be inhibited by a chemical analogue, hexyl-MAA. Also, MDA-MAA adducts were detected in the serum and aortic tissue of JCR diabetic/ atherosclerotic rats. These studies determined that commercially available antibodies to MDA predominantly react with the MAA adduct and are present in the JCR model of atherosclerosis in both the serum and the aortic tissue. Therefore, the immune response to MDA-modified proteins is most probably to the dihydropyridine structure (predominant epitope in MAA), which suggests that MAA adducts may play a role in the development and/or progression of atherosclerosis.
\end{abstract}

(C) 2010 Elsevier Inc. All rights reserved.
Studies have shown that MDA $^{1}$ is formed as a result of lipid peroxidation [1] and is capable of binding to various macromolecules $[2,3]$. Modification of proteins/lipoproteins has been associated with the development and/or progression of atherosclerotic disease [4,5]. Indeed, these modified proteins/lipoproteins have been found in the circulation [6,7] and atherosclerotic lesions [8-10] of patients with atherosclerotic disease. Within atherosclerotic lesions, a "protein quality disease" develops as the result of protein unfolding and modification of protein and/or macromolecular complex function at the cellular level [10]. Additionally, modified lipoproteins have been proven to be immunogenic, generating autoantibodies against epitopes within the apolipoprotein B-100 component [11].

The ability of these modified molecules to be highly immunogenic and proinflammatory poses a large threat to the vessel tissue if they are not removed, thereby drastically increasing the pathological

Abbreviations: MDA, malondialdehyde; MAA, malondialdehyde-acetaldehyde; AA, acetaldehyde.

* Corresponding author. Experimental Immunology Laboratory, Omaha Veterans Administration Medical Center, Omaha, NE 68105, USA. Fax: +1 4024490604.

E-mail address: mduryee@unmc.edu (M.J. Duryee). processes involved in the development and/or progression of atherosclerosis [12].

Additionally the initiation of antibody responses to MDA adducts has been used in the past as a marker of atherosclerosis [6,13-15]. However, the exact epitope of antibody binding and the role of this adduct in the pathogenesis of this disease remain relatively unknown. It has been demonstrated that MDA can break down to form acetaldehyde (AA) [1], and our group has shown that AA in the presence of MDA forms a unique malondialdehyde-acetaldehyde adduct we have termed MAA [16]. Important to this disease process is the observation that this adduct can initiate proinflammatory, profibrotic, and immune responses in the absence of adjuvant, resulting in the production of $\mathrm{T}$ cell and autoantibody responses [2,3,17].

More recently, MAA adducts have proven to be highly immunogenic in the absence of adjuvants [18]; they can bind scavenger receptors and elicit both proinflammatory and T-cell responses $[19,20]$. However, most important is the ability of the MAA adduct to generate antibody responses to the carrier protein, providing a potential mechanism by which tolerance to self proteins is abrogated, resulting in autoimmunity [21]. A concept that has been under investigation involves the lipid peroxidation of membranes to form MDA. This by-product can combine with proteins to modify lysine 
residues and form MDA adducts, one of which is the highly stable and biologically relevant MAA adduct [22].

There are a number of risk factors that predict the development and/or progression of atherosclerosis, including age, gender, obesity, hypertension, diabetes mellitus, serum cholesterol, and smoking, which increase the oxidative state [15]. Taking into account the number of aldehydes generated from smoking (AA from the cigarette itself) and the oxidative stress detected in obese patients with diabetes, a strong possibility exists for an increased presence of both MDA and AA in these patients, which may result in the formation of MAA adducts and the resultant protein quality disease [10]. Therefore, it was the purpose of this study to begin examining the relationship between MDA and MAA adducts and the potential role of adducts in the development and/or progression of atherosclerosis.

\section{Materials and methods}

\section{Animals}

Balb/c mice were purchased from the National Cancer Institute and maintained on a Purina rat chow diet. Male JCR (leptin receptor ${ }^{-/-}$) obese diabetic atherosclerotic rats were purchased from Charles Rivers Laboratories (Wilmington, MA, USA) and kept on a high-cholesterol diet for 6-8 months. Animals were allowed free access to their food and water up to $1 \mathrm{~h}$ before sacrifice. All procedures were approved by the Animal Subcommittee of the University of Nebraska Medical Center (UNMC; JCR rats) or Omaha VA Medical Center (Balb/c mice) in accordance with the National Institutes of Health Guide for the Care and Use of Laboratory Animals.

\section{Chemicals and proteins}

Bovine serum albumin (Alb) and rat serum albumin (RSA) were purchased from Calbiochem (La Jolla, CA, USA). AA was obtained from Aldrich Chemical Co. (Milwaukee, WI, USA). MDA was obtained as the sodium salt (MDA-Na) by treatment of tetramethoxypropane (Aldrich Chemical Co.) with $\mathrm{NaOH}$, according to the method of Iwata and Kikugawa [23]. Phytic acid (PA) and diethylenetriaminepentaacetic acid (DTPA) were obtained from Sigma Chemical Co. (St. Louis, MO, USA).

\section{Preparation of modified proteins}

Alb or RSA and low-density lipoprotein (LDL) were adjusted to $2 \mathrm{mg}$ and modified by reacting with increasing concentrations of MDA in the presence or absence of $1.0 \mathrm{mM} \mathrm{AA}$ in $0.1 \mathrm{M}$ phosphate buffer, $\mathrm{pH} 7.2$, containing $2 \mathrm{mM}$ DTPA and $2 \mathrm{mM} \mathrm{PA}$, at $37^{\circ} \mathrm{C}$ for 3 days, followed by dialysis against three changes of $0.1 \mathrm{M}$ sodium phosphate buffer for $24 \mathrm{~h}$ at $4{ }^{\circ} \mathrm{C}$ [16]. MAA-modified albumin was checked for modification by the amount of fluorescent MAA adduct present (excitation $398 \mathrm{~nm}$ and emission $460 \mathrm{~nm}$ ) using a Turner Biosystems (Sunnyvale, CA, USA) LS-5B spectrofluorimeter.

\section{Comparison of anti-MDA and MAA antibodies}

The specificity of the monoclonal and polyclonal anti-MAA antibodies [24] in conjunction with other commercially available anti-MDA antibodies (mouse 1F83 anti-MDA, Abcam, Cambridge, MA, USA; goat anti-MDA, Meridian Life Science, Saco, ME, USA; rabbit antiMDA, Calbiochem) were tested against Alb, and MAA-Alb modified at a ratio of 2:1 (2 mM MDA:1 mM AA), or increasing concentrations of MDA with Alb. For these experiments, 96-well Immulon IV (Nunc, Fisher Scientific, St. Louis, MO, USA) microtiter plates were coated with $2 \mu \mathrm{g}$ /well Alb, Alb modified with increasing concentrations of MDA, or MAA-Alb in bicarbonate buffer ( $\mathrm{pH} 9.6)$ as previously described [18]. After an overnight incubation at $37^{\circ} \mathrm{C}$, the plates were washed three times with phosphate-buffered saline containing $0.05 \%$ Tween 20 (PBST), and the MDA antibodies were diluted as determined by the manufacturer's directions and incubated at $37^{\circ} \mathrm{C}$ for $45 \mathrm{~min}$. MAA antibodies were diluted 1:1000 for the monoclonal and 1:2000 for the polyclonal. Plates were washed in PBST and a secondary antibody (HRPrabbit anti-mouse IgG, HRP-goat anti-rabbit IgG, or HRP-rabbit antigoat IgG; Sigma Chemical Co.) was added and incubated at $37^{\circ} \mathrm{C}$ for $45 \mathrm{~min}$. The plates were washed and TMB substrate was added. Color changes were monitored by an MRX II microplate reader (Dynatech, Chantilly, VA, USA) at $450 \mathrm{~nm}$. Standard curves were established using known concentrations of the appropriate mouse, goat, or rabbit IgG (Sigma Chemical Co.), and the concentrations of unknown samples were extrapolated by using Revelations Software (Dynatech). The means \pm SE of the relative concentrations of antibody from individual mice assayed in duplicate were subtracted from the activity on the unmodified protein and reported in nanograms per milliliter.

\section{Competitive ELISA demonstrating specificity to the MAA epitope}

To determine the specificity of the antibodies raised against the MAA epitope, a competitive ELISA was used. Briefly, ELISA plates were coated with MAA-Alb as described above and incubated overnight. A separate transfer plate was used to dilute the hexyl-MAA (a synthetic analogue) and the anti-MDA or anti-MAA antibodies. The hexyl-MAA was diluted twofold down the plate at a starting concentration of $2000 \mathrm{pmol} /$ well. The above antibodies were added at a dilution (previously determined) that would result in a 1.0 optical density reading on the spectrophotometer after 30 min of incubation. After an overnight incubation, the plate was washed and blocked, and the contents of the transfer plate were moved to the appropriate wells of the ELISA plate. After $1 \mathrm{~h}$ incubation at room temperature, the plate was washed and the secondary antibodies as outlined above were added for $30 \mathrm{~min}$. The absorbance was assessed as described above and the percentage inhibition determined using the formula below were OD is the optical density and BKG is the background:

\%inhibition $=\left(\mathrm{OD}_{\max }-\mathrm{BKG}\right)-\left(\mathrm{OD}_{\text {sample }}-\mathrm{BKG}\right) /\left(\mathrm{OD}_{\max }-\mathrm{BKG}\right) \times 100$.

\section{Immunization with MDA/MAA adducts}

To examine the immunogenicity of MDA and MAA adducts, Balb/c mice were immunized with increasing concentrations of MDAmodified Alb in the presence or absence of $1 \mathrm{mM}$ acetaldehyde. Before immunization, animals were prebled and serum tested for background levels of anti-MAA antibodies. Modified proteins were immunized at a concentration of $25 \mu \mathrm{g}$ weekly for 5 weeks in the absence of any adjuvants [18]. Following the immunization schedule, blood was collected using retro-orbital venous puncture and serum frozen at $-20{ }^{\circ} \mathrm{C}$ until processed.

\section{Determination of antibodies to MAA}

Serum from animals immunized with MDA or MAA adducts was screened for the presence of anti-MAA and anti-Alb antibodies. For these experiments plates were coated with 2:1 MAA-Alb or Alb as described above and incubated with the antiserum at a 1:1000 dilution. After an incubation period, a secondary HRP-rabbit anti-mouse antibody was added. Plates were developed, absorbance was determined, and concentrations were extrapolated as described above. Circulating antiMAA antibodies from prebleed serum samples prior to immunization were subtracted from the MAA-immunized mice and reported. 


\section{Screening of JCR rat serum for anti-MAA antibodies}

Serum from Sprague-Dawley and JCR rats was collected after 6 months on a high-cholesterol diet. The JCR rat on this diet has been used as a model of atherosclerosis as it has been shown to induce plaque formation and mimic human disease [25]. These studies were devised to evaluate the relevance of MDA/MAA-modified proteins and anti-MAA/MDA antibodies in an in vivo setting. To determine antibody concentrations, ELISA plates were coated with RSA, LDL, oxidized LDL, MAA LDL, and aortic tissue that were unmodified or modified with MAA as described above. A rat IgG standard was also coated on the plate to use as a standard curve. Antiserum was incubated at a 1:50 dilution and an HRP-rabbit anti-rat antibody used as the secondary detecting antibody. Plates were developed and concentrations determined as described above. To show specificity to the MAA epitope, RSA-MAA, hexyl-MAA, aortic tissue, and aortic tissue modified with MAA were used as inhibiting ligands. These experiments were designed in a manner similar to the hexyl-MAA studies described above. However, the proteins (inhibitors) were started at $1000 \mu \mathrm{g} /$ well and diluted twofold down the plate, the antiserum was added at $2 \times$ concentration, and the percentage inhibition was calculated as described above. Native Alb and RSA (unmodified) were used as negative controls and demonstrated no inhibitory properties of the antibody response.

\section{Determination of MAA antigens in aortic tissue}

Aortic tissues from Sprague-Dawley and JCR rats were lysed with PBS-RIPA buffer (PBS, pH 7.4, 0.5\% Triton X-100, 0.5\% sodium deoxycholate, $0.1 \%$ sodium dodecyl sulfate, $1 \mathrm{mM} \mathrm{Na-EDTA}$, and $5 \mu \mathrm{l} / \mathrm{ml}$ protease inhibitor cocktail; Sigma Chemical Co.) as described previously [26]. Lysates equivalent to $50 \mu \mathrm{g}$ were resolved under reducing conditions by SDS-PAGE on 10\% gels for detection of MAA antigens. Lysates equivalent to $100 \mu \mathrm{g}$ were resolved under reducing conditions by using an $8 \%$ SDS-PAGE. Proteins were transferred to Immuno-Blot polyvinylidene difluoride membranes (Bio-Rad, Hercules, CA, USA) and blocked 30 min in Odyssey blocking buffer (LiCor, Lincoln, $\mathrm{NE}, \mathrm{USA})$ at $37^{\circ} \mathrm{C}$. Blots were incubated with anti-MAA mouse monoclonal antibody (1:2000) dilution, followed by an IRDye-conjugated anti-mouse antibody (1:15,000; LiCor). Blots were scanned using an Odyssey IR scanner (LiCor) and bands were normalized to tubulin by using 1:4000 anti-tubulin mouse monoclonal antibody (Sigma Chemical Co.) and IRDye-conjugated anti-mouse antibody as an internal control. Data were expressed as the densitometric volume of MAA relative to the densitometric volume of tubulin for each lane.

\section{Statistical analysis}

Results are expressed as means \pm SEM. Statistical significance was achieved if $P$ values were less than 0.05 . All statistical analysis was performed using the SigmaStat (Jandel Scientific, 2002).

\section{Results}

Preliminary studies have suggested that the predominant adduct formed when MDA combines with proteins is the MAA epitope. This has been identified as a 1,4 dihydropyridine structure possessing strong fluorescence properties at an excitation of $398 \mathrm{~nm}$ and emission at $460 \mathrm{~nm}$. Therefore, assays were performed using this characteristic of MAA adducts to determine the amount of MAA modification on proteins modified with various concentrations of MDA. Table 1 shows the amount of MAA fluorescent modification $(\mathrm{nm} / \mathrm{mg})$ on MDA-modified albumin. By fluorescence assays, MDA alone begins to modify proteins with MAA when using as little as 0.5 to $1.0 \mathrm{mM}$ MDA. At concentrations of 10 to $50 \mathrm{mM}$ MDA, modification of the protein with MDA is similar to conditions under which MAA
Table 1

Fluorescent modification of MDA- or MAA-modified albumin

\begin{tabular}{lcc}
\hline Adduct $(\mathrm{mM})$ & \multicolumn{2}{c}{ MAA fluorescence $(\mathrm{nm} / \mathrm{mg})$} \\
\cline { 2 - 3 } & MDA only & MDA plus 1 mM AA \\
\hline MDA 0.5 & $0.18 \pm 0.06$ & $0.03 \pm 0.03$ \\
MDA 1.0 & $1.13 \pm 0.52$ & $23.06 \pm 4.28$ \\
MDA 2.0 & $4.87 \pm 0.78$ & $51.69 \pm 3.34$ \\
MDA 5.0 & $15.06 \pm 2.76$ & $141.86 \pm 11.21$ \\
MDA 10.0 & $32.82 \pm 7.63$ & $289.99 \pm 23.36$ \\
MDA 50.0 & $54.28 \pm 9.60$ & $504.90 \pm 58.43$ \\
MDA 100.0 & $29.20 \pm 3.36$ & $714.64 \pm 67.51$ \\
\hline
\end{tabular}

Bovine serum albumin was modified with increasing concentrations of MDA alone or MDA with $1 \mathrm{mM} \mathrm{AA}$ (MAA) and fluorescence was assayed at 398 and $460 \mathrm{~nm}$. Data are the means $\pm S E M$ of five separate experiments.

modification is performed using $2 \mathrm{mM}$ MDA and $1 \mathrm{mM}$ AA (standard conditions). The addition of MDA to proteins at concentrations from 0.5 to $100 \mathrm{mM}$ demonstrate a dose response with respect to MAA fluorescence $(0.18 \pm 0.06$ to $29.20 \pm 3.36 \mathrm{~nm} / \mathrm{mg})$. The addition of $1 \mathrm{mM}$ AA to the increasing concentrations of MDA showed a 5- to 10fold increase in MAA fluorescence. Also, measurements of the amount of fluorescence showed that $1 \mathrm{mM}$ AA increases the amount of MAA adducts formed as the concentration of MDA is increased. Therefore, these data show that although MDA alone will adduct protein with the MAA epitope, other MDA adducts must also form on proteins.

To further assess whether modification of proteins with MDA results in the modification of proteins with MAA or other MDA adducts, increasing doses of MDA were incubated with a protein and then examined immunologically for MDA and MAA adducts using commercially available anti-MDA antibodies and previously reported monoclonal (mouse $\times$ MAA) or polyclonal (rabbit $\times$ MAA) antibodies [24]. In Table 2, the activities of a commercial monoclonal antibody to MDA (Abcam) [3] and a monoclonal antibody prepared at UNMC [27] to the MAA epitope are compared on proteins modified with various concentrations of MDA (no AA added). As shown, both Abcam and UNMC monoclonal antibodies seem to recognize similar, if not the same, epitopes. The major difference may be in the sensitivity of the assays as the Abcam antibody is an IgG2a and the UNMC antibody is an IgG1.

The activity of the UNMC monoclonal antibody has been shown to be completely inhibited by the addition of the chemical analogue for MAA (hexyl-MAA) [28]. As shown in Fig. 1, both the UNMC and the Abcam monoclonal antibodies demonstrated similar competitive inhibition curves. The affinity of the two antibodies most probably accounts for the minor differences observed. Thus, the commercially available Abcam monoclonal antibody to MDA seems to actually be specific for the MAA epitope.

With respect to the polyclonal antibodies tested (Table 2), the UNMC polyclonal antibody reacted to the MDA-modified proteins in a dose-dependent manner. More importantly, it is an affinity-purified antibody to MAA that is completely inhibited by hexyl-MAA (Fig. 1) in a fashion similar to the two monoclonal antibodies. These data show that the MAA epitope is formed on proteins modified with MDA, dependent upon the concentration of MDA used. In contrast, the two polyclonal antibodies to MDA give variable results. Although both react to proteins modified with MDA in a concentration-dependent manner, two things are obvious: (1) The Calbiochem antibody reacts at a higher level (Table 2); however, this antibody is not inhibited by hexyl-MAA (Fig. 1). (2) The Biodesign polyclonal was inhibited by hexyl-MAA only to $50 \%$ (Fig. 1), indicating only partial reactivity to the MAA epitope. Interestingly, the Biodesign polyclonal is prepared by affinity purification on an MDA-modified Sepharose column, whereas the Calbiochem polyclonal is absorbed against protein carriers. Thus, the differences between these antibodies may be due to the way they were purified. These antibodies show that although the MAA epitope is produced relative to the amount of MDA present, there are other 
Table 2

Concentrations of antibodies to MDA adducts

\begin{tabular}{|c|c|c|c|c|c|}
\hline \multirow{2}{*}{$\begin{array}{l}\text { Concentration } \\
\text { of MDA }\end{array}$} & \multicolumn{2}{|l|}{ Monoclonal antibodies } & \multicolumn{3}{|l|}{ Polyclonal antibodies } \\
\hline & Abcam MS $\times$ MDA & UNMC Ms $\times$ MAA & Calbiochem $\mathrm{Rb} \times \mathrm{MDA}$ & Biodesign $\mathrm{Gt} \times \mathrm{MDA}$ & UNMC Rb $\times$ MAA \\
\hline MDA $0.5 \mathrm{mM}$ & $2.30 \times 10^{5} \pm 1.60 \times 10^{3}$ & 0 & $1.39 \times 10^{6} \pm 3.13 \times 10^{5}$ & $2.75 \times 10^{5} \pm 1.1 \times 10^{4}$ & $4.05 \times 10^{4} \pm 1.66 \times 10^{3}$ \\
\hline MDA $1.0 \mathrm{mM}$ & $2.97 \times 10^{5} \pm 1.67 \times 10^{4}$ & 0 & $2.83 \times 10^{6} \pm 3.28 \times 10^{5}$ & $6.25 \times 10^{5} \pm 2.19 \times 10^{4}$ & $6.67 \times 10^{4} \pm 5.72 \times 10^{3}$ \\
\hline MDA $2.5 \mathrm{mM}$ & $8.53 \times 10^{5} \pm 5.10 \times 10^{4}$ & $9.67 \times 10^{3} \pm 1.69 \times 10^{2}$ & $4.46 \times 10^{6} \pm 4.33 \times 10^{5}$ & $1.25 \times 10^{6} \pm 4.11 \times 10^{5}$ & $2.47 \times 10^{5} \pm 5.20 \times 10^{4}$ \\
\hline MDA $5.0 \mathrm{mM}$ & $3.25 \times 10^{6} \pm 2.99 \times 10^{5}$ & $9.99 \times 10^{4} \pm 4.79 \times 10^{3}$ & $4.60 \times 10^{6} \pm 9.49 \times 10^{5}$ & $2.15 \times 10^{6} \pm 5.61 \times 10^{5}$ & $3.83 \times 10^{5} \pm 2.68 \times 10^{4}$ \\
\hline MDA $10.0 \mathrm{mM}$ & $3.16 \times 10^{6} \pm 3.48 \times 10^{5}$ & $7.51 \times 10^{5} \pm 2.76 \times 10^{4}$ & $6.35 \times 10^{6} \pm 1.35 \times 10^{5}$ & $3.47 \times 10^{6} \pm 8.41 \times 10^{5}$ & $5.83 \times 10^{5} \pm 5.31 \times 10^{4}$ \\
\hline MDA $50.0 \mathrm{mM}$ & $2.50 \times 10^{6} \pm 5.10 \times 10^{5}$ & $1.54 \times 10^{6} \pm 3.00 \times 10^{5}$ & $1.08 \times 10^{7} \pm 2.23 \times 10^{5}$ & $5.07 \times 10^{6} \pm 8.12 \times 10^{5}$ & $7.05 \times 10^{5} \pm 5.40 \times 10^{4}$ \\
\hline MDA $100.0 \mathrm{mM}$ & $2.75 \times 10^{6} \pm 4.46 \times 10^{5}$ & $1.48 \times 10^{6} \pm 3.02 \times 10^{5}$ & $8.13 \times 10^{6} \pm 1.75 \times 10^{5}$ & $4.57 \times 10^{6} \pm 6.10 \times 10^{5}$ & $5.80 \times 10^{5} \pm 5.41 \times 10^{4}$ \\
\hline MAA 2:1 & $3.10 \times 10^{6} \pm 1.95 \times 10^{5}$ & $3.10 \times 10^{6} \pm 1.95 \times 10^{5}$ & $4.76 \times 10^{6} \pm 9.84 \times 10^{5}$ & $3.52 \times 10^{6} \pm 6.18 \times 10^{5}$ & $6.94 \times 10^{5} \pm 3.09 \times 10^{4}$ \\
\hline
\end{tabular}

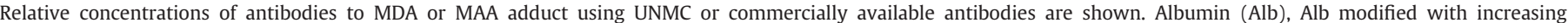

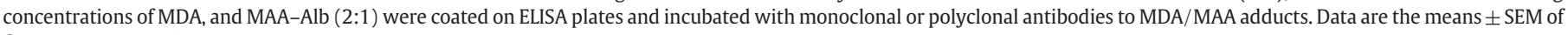
five separate experiments.

MDA adducts that may also form. These data are supported by the findings in Table 1 with respect to MAA fluorescence.

In an effort to determine the concentration of modified MDA that would induce an immune response to the 2:1 MAA adduct and/or the carrier protein, mice were immunized with increasing concentrations of MDA as the immunogen and the serum antibody concentrations tested for activity to Alb and Alb-MAA. Fig. 2 shows that there is a small (not significant) antibody response up to the concentration of $5 \mathrm{mM}$, in which the animals produce antibody to MAA-Alb but little to Alb. However, a concentration above $5 \mathrm{mM}$ increases the amount of anti-MAA antibodies in the serum of these mice. Therefore, the predominant antibody is to MAA and not to the carrier. This remains true as the amount of modification of albumin with MDA increased.

Mice were also injected with increasing concentrations of MDA incubated with $1 \mathrm{mM} \mathrm{AA}$ and their sera screened for the presence of anti-MAA antibodies. Fig. 3 shows that immunization at a ratio of as low as 1:1 (MDA:AA) induced antibody reactivity to the MAA product. This response increased twofold in the 2:1 immunizations and held constant throughout the increased addition of MDA. These antibody titers were not seen in the MDA-immunized animals until a concentration of $10 \mathrm{mM}$ was used (Fig. 2). These data show that only a small amount of AA incubated with MDA and a protein will cause significant antibody production to the MAA adduct, and higher levels of MDA most probably result in the modification of protein with another MDA adduct. One other important observation is the antibody response to the carrier protein Alb. These antibody responses were almost half the concentration of the immunizing agent. Once the concentration of MDA increased above $5 \mathrm{mM}$ the antibody to the

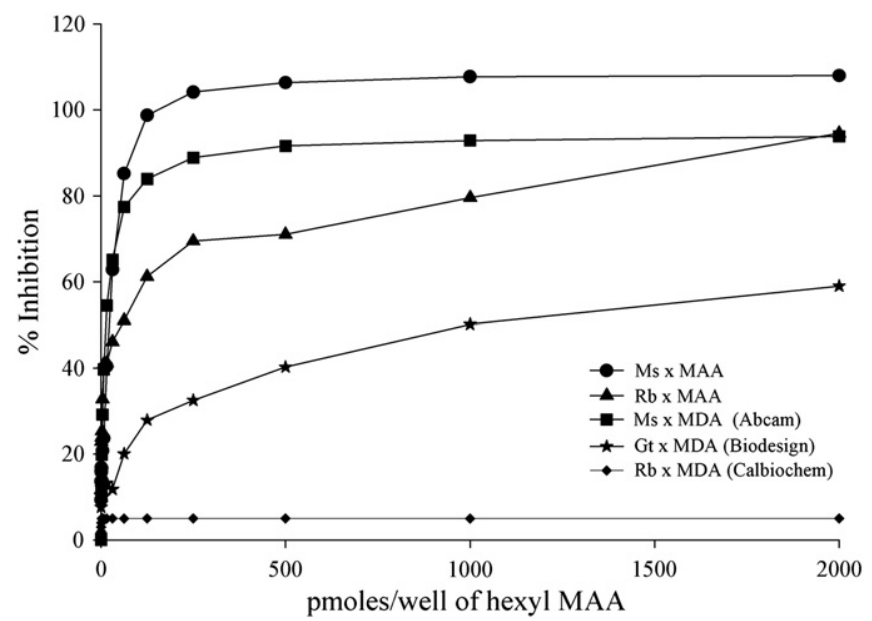

Fig. 1. Competitive inhibition of anti-MAA or anti-MDA antibodies binding to MAAmodified albumin. Anti-MAA or anti-MDA antibodies were incubated with increasing concentrations of hexyl-MAA (chemical analogue of MAA) and used in an ELISA to assess binding to MAA-modified albumin. Data are representative of five separate experiments. carrier protein was significantly decreased, leaving only the antibody to the MAA epitope.

Previous studies have demonstrated the presence of MAA adducts in atherosclerotic lesions from human subject aortas [29]. Therefore, experiments were performed to confirm the presence of antibodies to MAA in an animal model of atherosclerosis. Serum antibody concentrations of anti-MAA antibodies were determined using the JCR high-cholesterol animal model of vascular injury. Fig. 4 shows the presence of MAA antibodies in the JCR rat serum compared to the Sprague-Dawley control rat serum. Reactivity to aortic tissue modified with MAA and rat serum albumin MAA (modified self proteins) was increased approximately threefold compared to the control animals, indicating modification of a self protein in vivo. Also increased was LDL modified with MAA and aortic tissue compared to the Sprague-Dawley control rat serum. It is interesting to note that JCR rats had significant reactivity to aortic tissue compared to the control group, indicating an antibody response to self proteins. Specificity to these antibodies was demonstrated by inhibiting these responses with hexyl MAA (Fig. 5). Antibody reactivity was inhibited by $60 \%$ for RSA MAA, $40 \%$ for LDL MAA, and $40 \%$ for aortic MAA, indicating that the JCR serum had antibody to the self proteins modified with MAA. These antibody responses could not be completely inhibited with hexyl-MAA, indicating that part of the response could be to the carrier protein conjugate attached to MAA or possibly the 1:1 nonfluorescent MAA adduct. No inhibition was demonstrated using unmodified RSA or Alb alone.

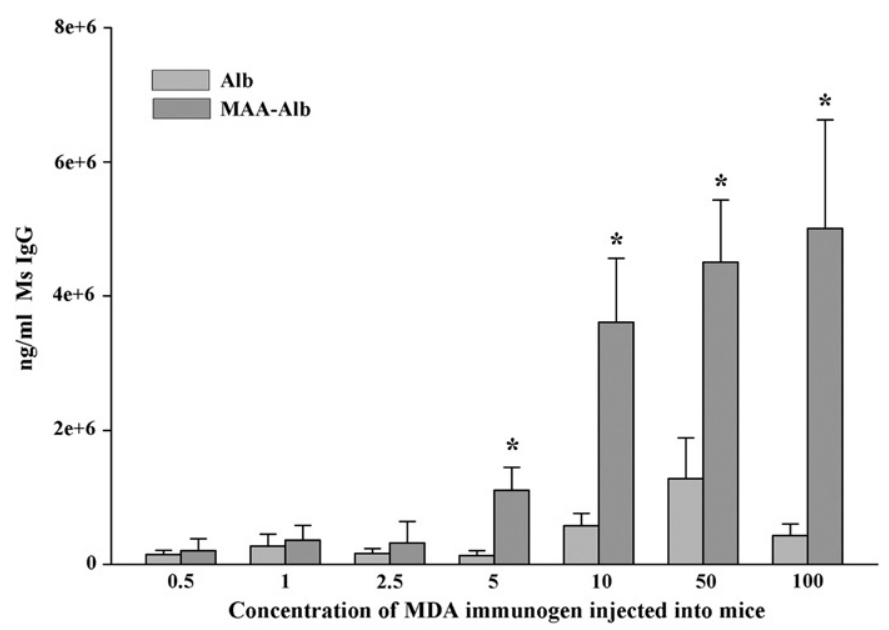

Fig. 2. In vivo response to MDA-modified albumin. Balb/c mice were immunized with albumin modified with increasing concentrations of MDA, and their serum was obtained and screened against 2:1 MAA-modified albumin for the presence of anti-MAA antibodies. Data expressed are the means \pm SEM of five animal experiments. ${ }^{*} P \leq 0.03$, significantly increased compared to Alb groups. 


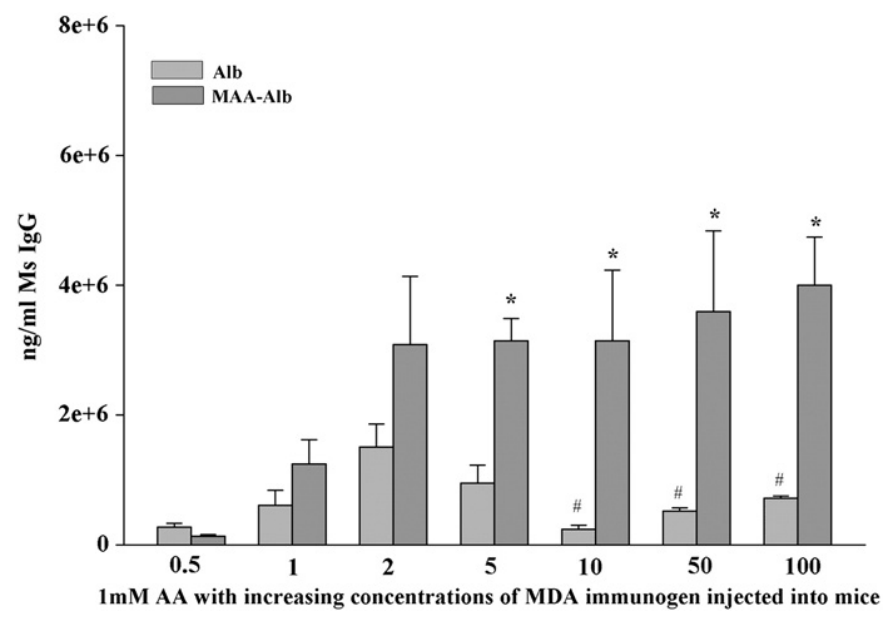

Fig. 3. In vivo response to MDA-modified albumin in the presence of $1 \mathrm{mM} \mathrm{AA}$. Balb/c mice were immunized with Alb modified with $1 \mathrm{mM}$ AA and increasing concentrations of MDA and their sera were screened against 2:1 MAA-modified albumin for the presence of anti-MAA antibodies. Data expressed are the means \pm SEM of five animal experiments. ${ }^{*} P \leq 0.029$, significantly increased compared to Alb groups. $\# P \leq 0.03$, significantly decreased compared to Alb in the 2:1 immunized mice.

To further prove the presence of MAA in the JCR model of atherosclerosis, aortic tissue from JCR and Sprague-Dawley control rats was excised and immunoprecipitated using the UNMC monoclonal MAA antibody. Densitometry of a band at $88 \mathrm{kDa}$ showed a threefold increase in the amount of MAA-modified proteins in the JCR aortic tissue compared to the control animal aortas (Fig. 6). These data in conjunction with the serum antibody levels clearly indicate the presence of both MAA-modified proteins and anti-MAA antibodies in the JCR model of atherosclerosis.

\section{Discussion}

Modifications of proteins or lipoproteins have many deleterious effects in a number of diseases including atherosclerosis. Plasmasoluble-protein modifications result in their binding to scavenger receptors, stimulating the release of proinflammatory cytokines, and becoming immunogenic, eliciting autoantibody formation and the generation of $\mathrm{T}$ cell responses [15]. The covalent binding of

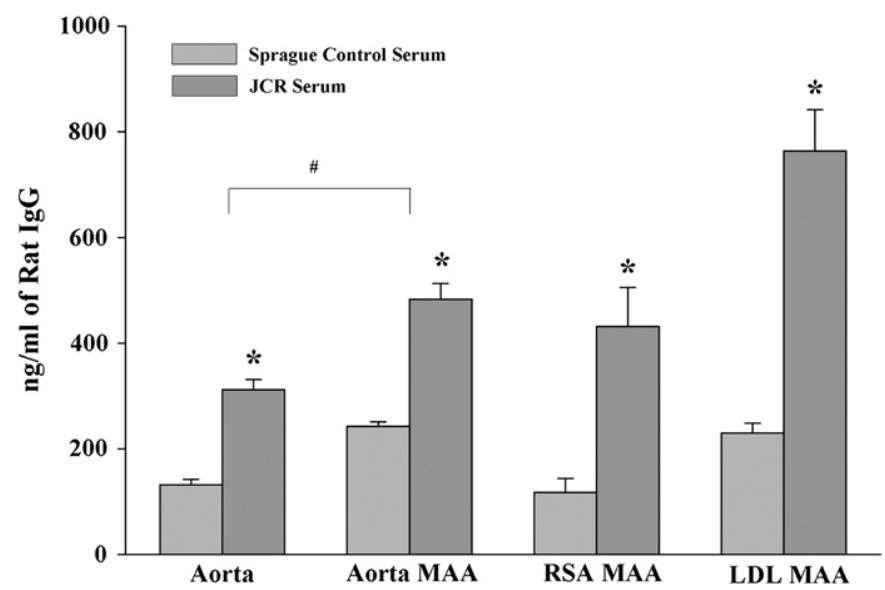

Fig. 4. Serum antibody concentrations to MAA-modified proteins in JCR rats. JCR rats were fed a high-cholesterol diet for 6-8 months. Serum was assayed for the presence of antibody to MAA using aortic tissue, aortic tissue modified with MAA, rat serum albumin modified with MAA, and LDL modified with MAA. Results are expressed in $\mathrm{ng} / \mathrm{ml}$ of rat IgG using a standard curve. Data are expressed as the means \pm SEM of six animal experiments. ${ }^{*} P \leq 0.004$, significantly increased compared to Sprague control serum. $\# P \leq 0.001$, significantly different comparing aorta to aorta MAA coating antigens.

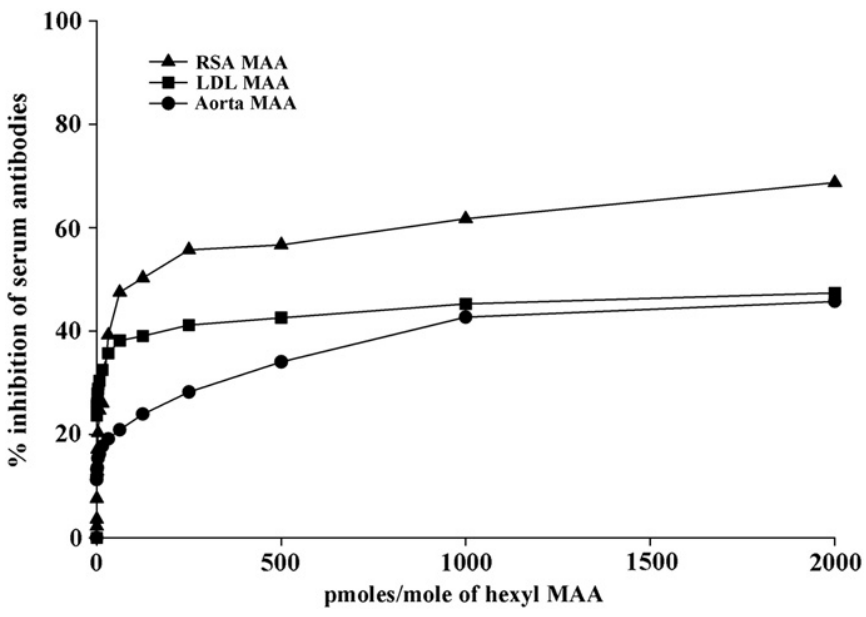

Fig. 5. Competitive inhibition of anti-MAA or aortic serum antibodies in JCR rats. Serum from JCR rats was incubated with increasing concentrations of hexyl-MAA and then incubated with corresponding antigen to look for inhibition binding to the epitope. Data are representative of three animal experiments.

acetaldehyde and malondialdehyde to proteins to form the MAA adduct has been demonstrated to be a major player in both alcoholic liver disease and, more recently, atherosclerosis [13,16,29]. The formation of these modified self proteins and their biological consequences provide a potential mechanism by which atherosclerotic lesions form. Therefore, it was the purpose of this study to evaluate the relationship of MAA modification of proteins with MDA modification that has been reported by other investigators $[1,16,17,23,30,31]$.

Previous studies have demonstrated that after incubation with MAA-albumin cultured rat heart endothelial cells up-regulate ICAM1 , VCAM, class I, and class II molecules on their surface and increase the release of tumor necrosis factor- $\alpha$ [29]. The MAA adduct in alcoholic liver disease has proven to bind scavenger receptors on liver sinusoidal endothelial cells, initiate $\mathrm{T}$ cell responses, increase the release of proinflammatory cytokines, and initiate the fibrogenic or wound-healing response $[19,20,32,33]$. This provides a possible mechanism by which MAA-modified proteins or lipoproteins bind scavenger receptors on the surface of endothelial cells of the aorta, increase cell surface markers of inflammation, and initiate macrophage migration into the intimal space. Binding to these scavenger receptors could overload the cells shunting the modified protein into the intima. As well, if dysfunctional protein clearance for these

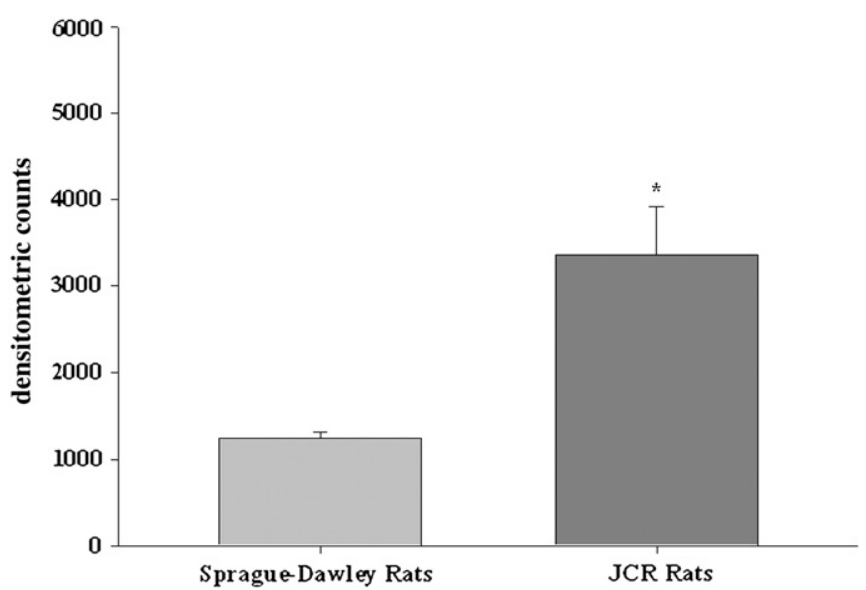

Fig. 6. Immunoprecipitation of MAA in aortic tissue from JCR rats. Aortic tissue from JCR or Sprague-Dawley rats was collected and immunoprecipitated using a monoclonal anti-MAA antibody. Presented data are of an $88-\mathrm{kDa}$ band expressed as the means \pm SEM of three animal experiments. ${ }^{*} P=0.005$, significantly different from Sprague control rats. 
adducts is impaired (i.e., protein chaperones and the ubiquitinproteasome pathway) and/or the modification of cellular membrane proteins is greater than clearance, then the buildup of dysfunctional proteins may result in disease. The resultant accumulation of dysfunctional proteins and protein aggregates (i.e., atherosclerotic amyloid) is hypothesized to play a critical role in vascular disease progression [10].

MDA-modified proteins or lipoproteins have long been thought to play an active role in the onset and/or progression of atherosclerosis $[6,15]$. The formation of these MDA adducts has been attributed to the breakdown of unsaturated fatty acids or lipid peroxidation reacting with lysine on proteins. Lipid peroxidation occurs when cells are exposed to reactive oxygen species causing cell walls to rupture and membrane lipids to degrade to the end-product malondialdehyde [6]. It has been shown that malondialdehyde is able to spontaneously break down and form acetaldehyde [1]. We hypothesize that if only a small concentration of acetaldehyde is present with malondialdehyde and a protein, then the stable adduct MAA can be formed as has previously been demonstrated. This is evident as demonstrated by the data above showing that MAA modification is present with as little as $0.5 \mathrm{mM}$ MDA in the presence of AA. Many, if not all, anti-MDA antibodies are generated using $10 \mathrm{mM}$ MDA [1,34-36]. In our hands, although mice immunized with $10 \mathrm{mM}$ MDA produced less antibody than mice immunized with MAA (2:1, MDA:AA) ratio, antibody was detected. Also, these data prove that just a small amount of AA can cause MDA to react with proteins to form the MAA adduct and subsequently antibody formation takes place. Some of the commercial antibodies could not be completely inhibited with hexyl-MAA, the synthetic analogue, which mimics the 4-methyl-1,4-dihydropyridine3,5-dicarbaldehyde derivative of lysine. One potential reason for this incomplete inhibition would be that some of these antibodies recognize the 1:1 linear MAA adduct that forms when excess AA is present in the reaction $[16,24,28,37]$. This could explain why when the level of MDA is increased (which can break down to form AA) the antibody response to MAA is decreased.

One question that arises is how these two chemicals (AA and MDA) are present at the same time in the body to make these modified self proteins. MDA from lipid peroxidation could be attributed to the high-fat diet people consume every day, especially as increased fatty liver (alcoholic or nonalcoholic) and the incidence of atherosclerosis are on the rise. AA could come from the breakdown of MDA to AA or the oxidation of alcohol from drinking [38], fermentation of food in the gut [39], metabolism of threonine by threonine aldolase in rodents only [40,41], and smoking [42]. In fact, cigarette smoke extract has been shown to react with MDA and proteins to make MAA-modified proteins [43]. Given the highly oxidative state of smoking, it has been shown that oxidative stress increases the amount of lipid peroxidation in the lungs, which increases the plasma and tissue levels of MDA [44-46]. Importantly, this could be one potential mechanism of how cigarette smoking may be a cofactor and increase the risk of cardiovascular disease.

In conclusion, commercially available antibodies to MDA were shown to predominantly react with the MAA adduct. Thus, these data suggest that many of these commercially available antibodies have specificity for the dihydropyridine structure, as confirmed by inhibition studies using an analogue to MAA. MAA-modified proteins induce immune responses at physiological modifications better than MDA alone. Proteins modified with MAA are present in the JCR rat model of atherosclerosis in both the serum and the aortic tissue. Modification of carrier proteins with MAA provides a potential mechanism by which self proteins are modified and recognized by the immune system. Therefore, the immune response to MDAmodified proteins is most probably to the dihydropyridine structure (predominant epitope in MAA) and suggests that MAA adducts may play a role in the development and/or progression of vascular disease such as atherosclerosis.

\section{Acknowledgments}

This work was supported by National Institutes of Health Grants R01 AA10435, R37 AA07818, and R21 AA15505-01A2 and also by the Department of Veterans Affairs National Merit Review Program and the Department of Internal Medicine at the University of Nebraska Medical Center.

\section{References}

[1] Uchida, K. Lipofuscin-like fluorophores originated from malondialdehyde. Free Radic. Res, 40:1335-1338; 2006.

[2] Steinbrecher, U. P.; Fisher, M.; Witztum, J. L.; Curtiss, L. K. Immunogenicity of homologous low density lipoprotein after methylation, ethylation, acetylation, or carbamylation: generation of antibodies specific for derivatized lysine. J. Lipid Res. 25:1109-1116; 1984.

[3] Yamada, S.; Kumazawa, S.; Ishii, T.; Nakayama, T.; Itakura, K.; Shibata, N.; Kobayashi, M.; Sakai, K.; Osawa, T.; Uchida, K. Immunochemical detection of a lipofuscin-like fluorophore derived from malondialdehyde and lysine. J. Lipid Res. 42:1187-1196; 2001.

[4] Fu, S.; Davies, M. J.; Stocker, R.; Dean, R. T. Evidence for roles of radicals in protein oxidation in advanced human atherosclerotic plaque. Biochem. J. 333 (Pt 3): 519-525; 1998

[5] Heinecke, J. W. Oxidants and antioxidants in the pathogenesis of atherosclerosis: implications for the oxidized low density lipoprotein hypothesis. Atherosclerosis 141:1-15; 1998.

[6] Holvoet, P.; Perez, G.; Zhao, Z.; Brouwers, E.; Bernar, H.; Collen, D. Malondialdehyde-modified low density lipoproteins in patients with atherosclerotic disease. J. Clin. Invest. 95:2611-2619; 1995.

[7] Palinski, W.; Horkko, S.; Miller, E.; Steinbrecher, U. P.; Powell, H. C.; Curtiss, L. K.; Witztum, J. L. Cloning of monoclonal autoantibodies to epitopes of oxidized lipoproteins from apolipoprotein E-deficient mice: demonstration of epitopes of oxidized low density lipoprotein in human plasma. J. Clin. Invest. 98:800-814; 1996.

[8] Palinski, W.; Rosenfeld, M. E.; Yla-Herttuala, S.; Gurtner, G. C.; Socher, S. S.; Butler, S. W.; Parthasarathy, S.; Carew, T. E.; Steinberg, D.; Witztum, J. L. Low density lipoprotein undergoes oxidative modification in vivo. Proc. Natl. Acad. Sci. USA 86: 1372-1376; 1989.

[9] Yla-Herttuala, S.; Palinski, W.; Rosenfeld, M. E.; Parthasarathy, S.; Carew, T. E.; Butler, S.; Witztum, J. L.: Steinberg, D. Evidence for the presence of oxidatively modified low density lipoprotein in atherosclerotic lesions of rabbit and man. J. Clin. Invest. 84:1086-1095; 1989.

[10] Herrmann, J.; Soares, S. M.; Lerman, L. O.; Lerman, A. Potential role of the ubiquitin-proteasome system in atherosclerosis: aspects of a protein quality disease. J. Am. Coll. Cardiol. 51:2003-2010; 2008.

[11] Horkko, S.; Binder, C. J.; Shaw, P. X.; Chang, M. K.; Silverman, G.; Palinski, W.; Witztum, J. L. Immunological responses to oxidized LDL. Free Radic. Biol. Med. 28: 1771-1779; 2000

[12] Matsuura, E.; Lopez, L. R. Autoimmune-mediated atherothrombosis. Lupus 17: 878-887; 2008 .

[13] Chou, M. Y.; Fogelstrand, L.; Hartvigsen, K.; Hansen, L. F.; Woelkers, D.; Shaw, P. X.; Choi, J.; Perkmann, T.; Backhed, F.; Miller, Y. I.; Horkko, S.; Corr, M.; Witztum, J. L.; Binder, C. J. Oxidation-specific epitopes are dominant targets of innate natural antibodies in mice and humans. J. Clin. Invest 119:1335-1349; 2009.

[14] Fredrikson, G. N.; Hedblad, B.; Berglund, G.; Alm, R.; Ares, M.; Cercek, B.; Chyu, K. Y.; Shah, P. K.; Nilsson, J. Identification of immune responses against aldehyde-modified peptide sequences in apoB associated with cardiovascular disease. Arterioscler. Thromb. Vasc. Biol. 23:872-878; 2003.

[15] Stocker, R.; Keaney Jr., J. F. Role of oxidative modifications in atherosclerosis. Physiol. Rev. 84:1381-1478; 2004.

[16] Tuma, D. J.; Thiele, G. M.; Xu, D; Klassen, L. W: Sorrell, M. F. Acetaldehyde and malondialdehyde react together to generate distinct protein adducts in the liver during long-term ethanol administration. Hepatology 23:872-880; 1996.

[17] Kikugawa, K.; Kato, T.; Iwata, A. Determination of malonaldehyde in oxidized lipids by the Hantzsch fluorometric method. Anal. Biochem. 174:512-521; 1988.

[18] Thiele, G. M.; Tuma, D. J.; Willis, M. S.; Miller, J. A.; McDonald, T. L.; Sorrell, M. F.; Klassen, L. W. Soluble proteins modified with acetaldehyde and malondialdehyde are immunogenic in the absence of adjuvant. Alcohol. Clin. Exp. Res. 22: 1731-1739; 1998

[19] Duryee, M. J.; Klassen, L. W.; Freeman, T. L.; Willis, M. S.; Tuma, D. J.; Thiele, G. M. Lipopolysaccharide is a cofactor for malondialdehyde-acetaldehyde adductmediated cytokine/chemokine release by rat sinusoidal liver endothelial and Kupffer cells. Alcohol. Clin. Exp. Res. 28:1931-1938; 2004.

[20] Willis, M. S.; Thiele, G. M.; Tuma, D. J.; Klassen, L. W. T cell proliferative responses to malondialdehyde-acetaldehyde haptenated protein are scavenger receptor mediated. Int. Immunopharmacol. 3:1381-1399; 2003.

[21] Duryee, M. J.; Willis, M. S.; Freeman, T. L.; Kuszynski, C. A.; Tuma, D. J.; Klassen, L. W.; Thiele, G. M. Mechanisms of alcohol liver damage: aldehydes, scavenger receptors, and autoimmunity. Front. Biosci. 9:3145-3155; 2004.

[22] Uchida, K.; Sakai, K.; Itakura, K.; Osawa, T.; Toyokuni, S. Protein modification by lipid peroxidation products: formation of malondialdehyde-derived $N^{\varepsilon}$-(2-propenol) lysine in proteins. Arch. Biochem. Biophys. 346:45-52; 1997. 
[23] Iwata, A.; Kikugawa, K. Fluorometric determination of malonaldehyde in oxidized lipids. Chem. Pharm. Bull. (Tokyo) 35:5020-5023; 1987.

[24] Thiele, G. M.; Tuma, D. J.; Miller, J. A.; Wegter, K. M.; McDonald, T. L.; Klassen, L. W. Monoclonal and polyclonal antibodies recognizing acetaldehyde-protein adducts. Biochem. Pharmacol. 56:1515-1523; 1998.

[25] Vine, D. F.; Takechi, R.; Russell, J. C.; Proctor, S. D. Impaired postprandial apolipoprotein-B48 metabolism in the obese, insulin-resistant JCR:LA-cp rat: increased atherogenicity for the metabolic syndrome. Atherosclerosis 190: 282-290; 2007.

[26] Schaffert, C. S.; Sorrell, M. F.; Tuma, D. J. Expression and cytoskeletal association of integrin subunits is selectively increased in rat perivenous hepatocytes after chronic ethanol administration. Alcohol. Clin. Exp. Res. 25: 1749-1757; 2001.

[27] Thiele, G. M.; Klassen, L. W.; Tuma, D. J. Formation and immunological properties of aldehyde-derived protein adducts following alcohol consumption. Meth. Mol. Biol. 447:235-257; 2008.

[28] Xu, D.; Thiele, G. M.; Kearley, M. L.; Haugen, M. D.; Klassen, L. W.; Sorrell, M. F.; Tuma, D. J. Epitope characterization of malondialdehyde-acetaldehyde adducts using an enzyme-linked immunosorbent assay. Chem. Res. Toxicol. 10:978-986; 1997.

[29] Hill, G. E.; Miller, J. A.; Baxter, B. T.; Klassen, L. W.; Duryee, M. J.; Tuma, D. J.; Thiele, G. M. Association of malondialdehyde-acetaldehyde (MAA) adducted proteins with atherosclerotic-induced vascular inflammatory injury. Atherosclerosis 141: 107-116; 1998.

[30] Mooradian, A. D.; Reinacher, D.; Li, J. P.; Pinnas, J. L. Malondialdehyde modification of proteins in vitro is enhanced in the presence of acetaldehyde. Nutrition 17: 619-622; 2001.

[31] Tsai, L.; Szweda, P. A.; Vinogradova, O.; Szweda, L. I. Structural characterization and immunochemical detection of a fluorophore derived from 4-hydroxy-2-nonenal and lysine. Proc. Natl. Acad. Sci. USA 95:7975-7980; 1998.

[32] Duryee, M. J.; Freeman, T. L.; Willis, M. S.; Hunter, C. D.; Hamilton, B. C.; Suzuki III, H.; Tuma, D. J.; Klassen, L. W.; Thiele, G. M. Scavenger receptors on sinusoidal liver endothelial cells are involved in the uptake of aldehyde-modified proteins. Mol. Pharmacol. 68:1423-1430; 2005.

[33] Thiele, G. M.; Duryee, M. J.; Freeman, T. L.; Sorrell, M. F.; Willis, M. S.; Tuma, D. J.; Klassen, L. W. Rat sinusoidal liver endothelial cells (SECs) produce pro-fibrotic factors in response to adducts formed from the metabolites of ethanol. Biochem. Pharmacol. 70:1593-1600; 2005.
[34] Bourdel-Marchasson, I.; Delmas-Beauvieux, M. C.; Peuchant, E.; Richard-Harston, S.; Decamps, A.; Reignier, B.; Emeriau, J. P.; Rainfray, M. Antioxidant defences and oxidative stress markers in erythrocytes and plasma from normally nourished elderly Alzheimer patients. Age Ageing 30:235-241; 2001.

[35] Ishii, T.; Kumazawa, S.; Sakurai, T.; Nakayama, T.; Uchida, K. Mass spectroscopic characterization of protein modification by malondialdehyde. Chem. Res. Toxicol. 19:122-129; 2006.

[36] Kinalski, M.; Sledziewski, A.; Telejko, B.; Zarzycki, W.; Kinalska, I. Lipid peroxidation and scavenging enzyme activity in streptozotocin-induced diabetes. Acta Diabetol. 37:179-183; 2000.

[37] Klassen, L. W.; Thiele, G. M. Immune reactivity to proteins biotransformed by alcohol metabolites. Alcohol. Clin. Exp. Res. 22:204S-207S; 1998.

[38] Hawkins, R. D.; Kalant, H. The metabolism of ethanol and its metabolic effects. Pharmacol. Rev. 24:67-157; 1972.

[39] Visapaa, J. P.; Jokelainen, K.; Nosova, T.; Salaspuro, M. Inhibition of intracolonic acetaldehyde production and alcoholic fermentation in rats by ciprofloxacin. Alcohol. Clin. Exp. Res. 22:1161-1164; 1998.

[40] Edgar, A. J. Mice have a transcribed L-threonine aldolase/GLY1 gene, but the human GLY1 gene is a non-processed pseudogene. BMC Genomics 6:32; 2005.

[41] Ma, X. L.; Baraona, E.; Hernandez-Munoz, R.; Lieber, C. S. High levels of acetaldehyde in nonalcoholic liver injury after threonine or ethanol administration. Hepatology 10 933-940; 1989.

[42] Seeman, J. I.; Dixon, M.; Haussmann, H. J. Acetaldehyde in mainstream tobacco smoke: formation and occurrence in smoke and bioavailability in the smoker. Chem. Res. Toxicol. 15:1331-1350; 2002.

[43] Freeman, T. L.; Haver, A.; Duryee, M. J.; Tuma, D. J.; Klassen, L. W.; Hamel, F. G.; White, R. L.; Rennard, S. I.; Thiele, G. M. Aldehydes in cigarette smoke react with the lipid peroxidation product malonaldehyde to form fluorescent protein adducts on lysines. Chem. Res. Toxicol. 18:817-824; 2005

[44] Harats, D.; Ben-Naim, M.; Dabach, Y.; Hollander, G.; Stein, O.; Stein, Y. Cigarette smoking renders LDL susceptible to peroxidative modification and enhanced metabolism by macrophages. Atherosclerosis 79:245-252; 1989.

[45] Nielsen, F.; Mikkelsen, B. B.; Nielsen, J. B.; Andersen, H. R.; Grandjean, P. Plasma malondialdehyde as biomarker for oxidative stress: reference interval and effects of life-style factors. Clin. Chem. 43:1209-1214; 1997.

[46] Sandhir, R.; Subramanian, S.; Koul, A. Long-term smoking and ethanol exposure accentuates oxidative stress in hearts of mice. Cardiovasc. Toxicol. 3:135-140; 2003. 